\title{
Exploratory study of landfill leachate toxic effects to sludge characterized by endogenous respiration rate constant
}

\author{
Xin Chen \\ Chongqing Jianzhu College, Chongqing, China \\ E-mail:94444724@qq.com \\ www.cctc.cq.cn
}

\begin{abstract}
Endogenous respiration rate constant $\left(\mathrm{k}^{\prime}\right)$ reflects the activity of activated sludge. The activity of activated sludge will be decreased after poisoning effect of landfill leachate, the $\mathrm{k}^{\prime}$ will also change. Therefore, $\mathrm{k}^{\prime}$ can reflect the toxicity of landfill leachate to activated sludge. Measured the $\mathrm{k}^{\prime}$ values of activated sludge after poisoning effect of two landfill leachates at 7 concentrations, to verify the correlation between $\mathrm{k}^{\prime}$ values and concentrations of landfill leachate. The results show that, $\mathrm{k}^{\prime}$ and the concentration of landfill leachate showed a strong linear correlation, R2 are 0.930 and 0.956 respectively. Thus, using $\mathrm{k}^{\prime}$ characterized the toxicity of landfill leachate to activated sludge is scientific and rational.
\end{abstract}

Keywords: Landfill Leachate, Endogenous Respiration Rate Constant, Activated Sludge, Toxicity

\section{Introduction}

The main ways to deal with municipal solid waste is sanitary landfill and incineration, these two treatment methods both will produce a large quantity of landfill leachate, the landfill leachate is an important issue faced in the process of garbage treatment. At present, the adopted treatment method of landfill leachate is mainly still the biological treatment, the main way of which is to join up the sewage treatment plant for combined treatment and individual treatment. However, landfill leachate is a kind of high concentration organic waste water, whose component is complex and difficult to be degraded. The leachate contains a large quantity of difficult biodegradable organic substances and a variety of poisonous and harmful substances, containing a large quantity of heavy metal ions, and it also has high ammonia nitrogen, high salt content and other characteristics, showing a strong biological toxicity, which can inhibit the sludge microbial activity in the biological treatment system, and causes the difficulty for the biological treatment of landfill leachate [1, 2]. Judging the poisonous effect of landfill leachate on the sludge microorganism in the biological 
treatment system, has a strong guiding role for the specific processing selection in the landfill leachate biological treatment process, as well as the determination of various operating parameters.

When the activated sludge microorganisms are in the endogenous respiration, the microorganisms use their own cell substances as a decomposition of the matrix, the respiration rate is constant, and their respiration rate constant is called endogenous respiration rate constant $\mathrm{k}^{\prime}[3]$. The endogenous respiration rate constant k' of the sludge can reflect the activity intensity of the sludge itself, after the activated sludge is affected by the landfill leachate, its activity has declined and even died[4], the endogenous respiration rate constant $\mathrm{K}$ ' will also be changed with it, after the effect of the leachate, the endogenous respiration rate constant $\mathrm{K}$ ' size can reflect the biological toxicity size of the leachate on the sludge, so using $\mathrm{K}$ ' to characterize the biological toxicity of the leachate on the sludge has certain feasibility. This paper mainly investigates the feasibility and reasonability that the endogenous respiration rate constant $\mathrm{k}^{\prime}$ of the sludge characterizes the biological toxicity that the landfill leachate has on the sludge through experiments.

\section{Materials and Methods}

\subsection{Landfill leachate and activated sludge}

The experiment adopts two kinds of landfill leachate, which are taken from Long tousi Landfill Site and Tongxing Garbage Incineration Plant.

The landfill leachate of Longtou Temple Landfill Site is the later period leachate whose landfill time exceeds ten years, and the average water quality situations are: COD 4500 mg/L, B/C 0.114, NH3-H 2550 mg/L, pH8.22.

The landfill leachate of Tongxing Garbage Incineration Plant comes from the garbage storage pond before burning, and the average water quality situations are: COD 50000 mg/L, B/C 0.461, NH3-H 1600 mg/L,pH 6.30.

The experimental sludge is taken from the aeration tank of Tangjiatuo Waste water Treatment Plant Chongqing of Chongqing Municipality.

\subsection{Experimental instruments and devices}

The main instruments of the experiment are YSI DO200 dissolved oxygen meter, $78 \mathrm{HW}-1$ type magnetic mixer, $500 \mathrm{~mL}$ wide mouth bottle. The abbreviated drawing of experimental equipment is as shown in Figure 1. 


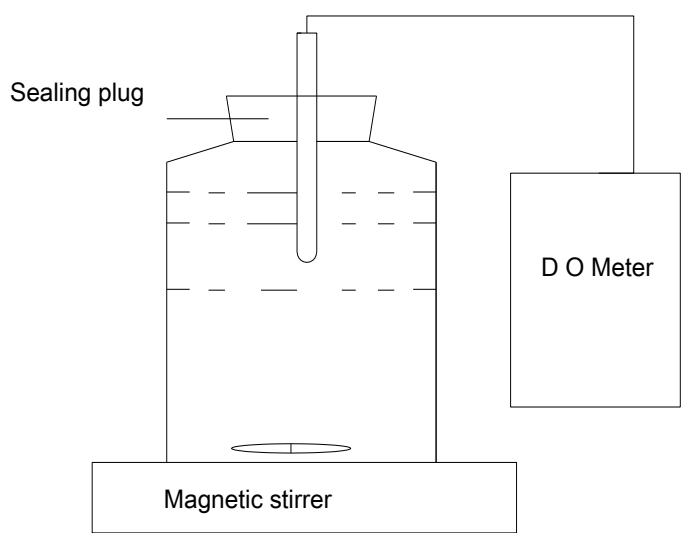

Fig. 1. The sketch of DO measuring device

\subsection{Experimental methods and procedures}

(1)Respectively dilute two kinds of landfill leachate into 5\%,10\%, 20\%, 40\%, $60 \%, 80 \%, 100 \%$ of 7 concentration levels, respectively mensurate the endogenous respiration rate constant $\mathrm{K}$ value of activated sludge after each level effect.

(2) Take a certain amount of activated sludge, add water to it and dilute it to MLSS for $2000 \mathrm{mg} / \mathrm{L}$ or so, then take $500 \mathrm{ml}$ to put it in $1 \mathrm{~L}$ beaker, 1 hours aeration, make the microorganism in the state of starvation, precipitate it for 30 minutes, use siphon pipe to remove above $200 \mathrm{ml}$ clear solution.

(3) A: Mensurate the endogenous respiration rate constant $\mathrm{K}$ value of primary sludge without the leachate effect. Add $200 \mathrm{~mL}$ clear water, after oxygen-enriched, transfer it to $500 \mathrm{ml}$ wide mouth bottle, stirring with a magnetic mixer under the normal temperature $\left(20-30^{\circ} \mathrm{C}\right)$, use the dissolved oxygen meter to mensurate the $\mathrm{DO}$ value of the former 30 minutes, and read the values once every minute.

$B$ : Mensurate the endogenous respiration rate constant $\mathrm{K}$ value of the sludge after the leachate effect. Add $200 \mathrm{~mL}$ landfill leachate of each concentration diluted, 2 hours aeration, make the microorganism decompose fully the organic matter in it, precipitate it for 30 minutes, use the siphon pipe to remove above $200 \mathrm{ml}$ clear solution. Finally, add $200 \mathrm{~mL}$ clear water, after oxygen-enriched, transfer it to $500 \mathrm{ml}$ wide mouth bottle, stir it with a magnetic mixer, use the dissolved oxygen meter to mensurate the DO value of the former 30 minutes, and read the values once every minute. 


\section{Results and Analysis}

Major headings should be typeset in boldface with the first letter of important words capitalized.

\subsection{Experimental results}

The experiment results are shown in Table 1.

Table 1. The results of DO.

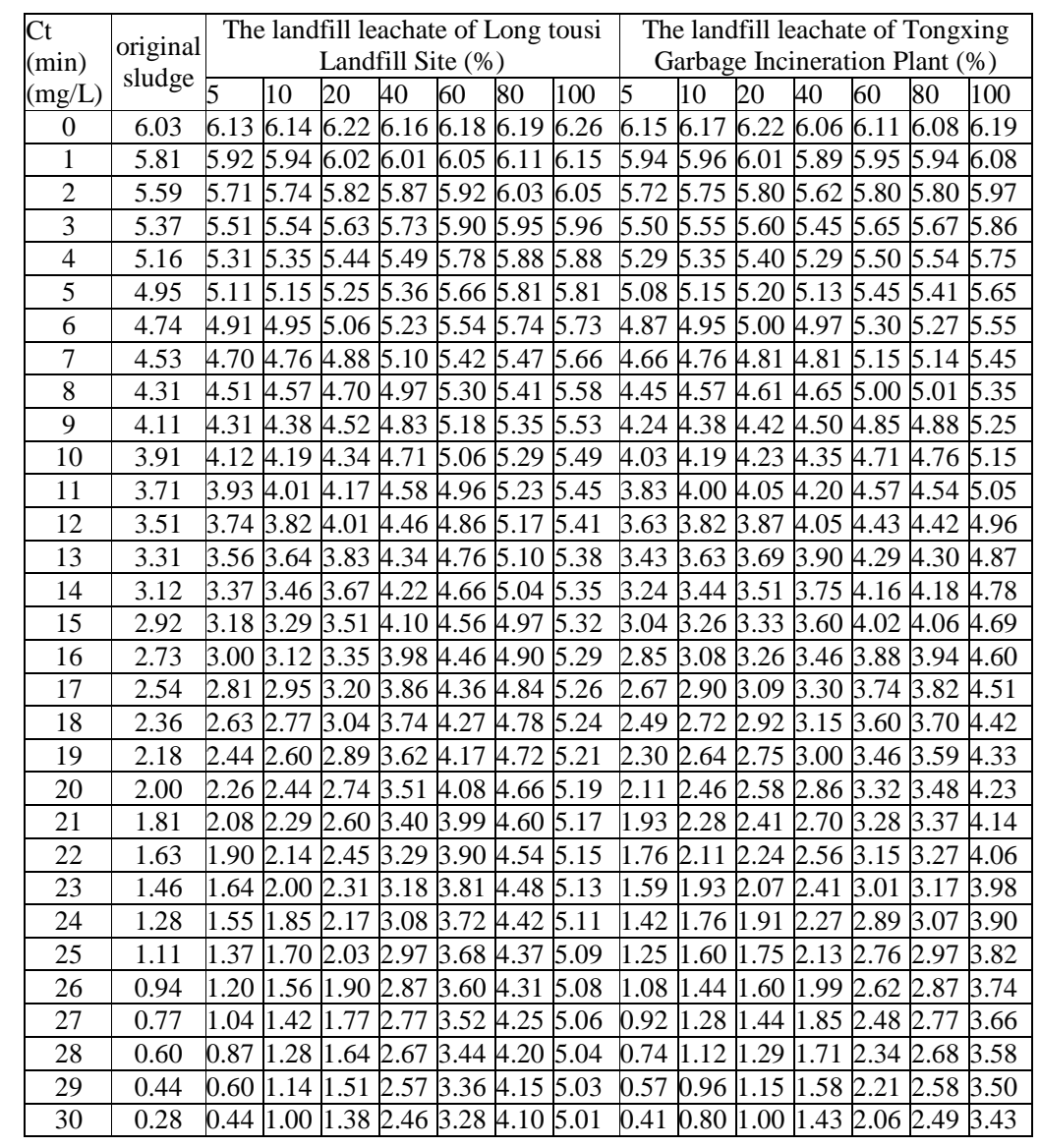

\subsection{Calculation of the endogenous respiration rate constant $K$ 'value of the sludge}

In the experimental measurement system, the consumption rate of dissolved oxygen in the solution is proportional to the concentration of dissolved oxygen 
in the system, if it complies with the following reaction equations; it is the first level reaction:

$$
-\mathrm{dC} / \mathrm{dt}=\mathrm{k} \cdot \mathrm{S} \cdot \mathrm{C}
$$

$-\mathrm{dC} / \mathrm{dt}$ - the concentration of dissolved oxygen is with the change rate of time $\mathrm{mg} / \mathrm{L} \cdot \mathrm{min}$;

$\mathrm{C}$ - the dissolved oxygen amount in solution $\mathrm{mg} / \mathrm{L}$;

$\mathrm{S}$ - the biomass in the biological reaction system $\mathrm{mg} / \mathrm{L}$;

$\mathrm{K}$ - the Reaction rate constant min-1

In the given reaction system, if the concentration of $S$ is unchanged, there will be:

$$
-\mathrm{dC} / \mathrm{dt}=\mathrm{k} \cdot \mathrm{C}
$$

And make, $\mathrm{t}=0, \mathrm{C}=\mathrm{C} 0$, for $(2)$ equation at $(0, \mathrm{t})$ interval the integral is got:

$$
-\ln \mathrm{Ct} / \mathrm{C} 0=\mathrm{k}^{\prime} \cdot \mathrm{t}
$$

$\mathrm{K}$ '- the reaction rate constant of a given reaction system min-1;

$\mathrm{C} 0, \mathrm{Ct}$ - the initial dissolved oxygen and the dissolved oxygen content of $\mathrm{t}$ time in the reaction system.

Take $-\ln \mathrm{Ct} / \mathrm{C} 0$ in contrast with the reaction time $\mathrm{t}$ to map, the straight slope got by the linear regression is just the endogenous respiration rate constant $k$ ' [5] in the sludge.

According to the experimental results, calculate in accordance with the above methods to get $\mathrm{K}$ ' value of various concentrations, see Table 2.

Table 2. The Results of k' at various concentrations.

\begin{tabular}{|l|l|l|l|l|l|l|l|l|}
\hline $\begin{array}{l}\text { k' } \\
(10-2 m i n-1)\end{array}$ & $\begin{array}{l}\text { original } \\
\text { sludge }\end{array}$ & $5 \%$ & $10 \%$ & $20 \%$ & $40 \%$ & $60 \%$ & $80 \%$ & $100 \%$ \\
\hline Long Tousi & 8.71 & 7.49 & 5.81 & 4.90 & 3.02 & 2.15 & 1.37 & 0.65 \\
\hline Tong Xing & 8.71 & 7.89 & 6.29 & 5.75 & 4.60 & 3.51 & 3.01 & 1.97 \\
\hline
\end{tabular}

\subsection{Analysis and discussion}

Make a linear correlation analysis of $\mathrm{K}$ 'value and concentration value which are obtained at different concentrations of two kinds of landfill leachate, the linear fitting graph is as shown in Figure 2 and figure 3. The relevant coefficient $R^{2}$ is respectively 0.930 and 0.956 , which all show a strong linear correlation, $\mathrm{K}$ 'value can reflect the biological toxicity change of the sludge caused by the leachate concentration change, so it is indicated that, using characterizes the biological toxicity that the landfill leachate has on the sludge is scientific and reasonable. 


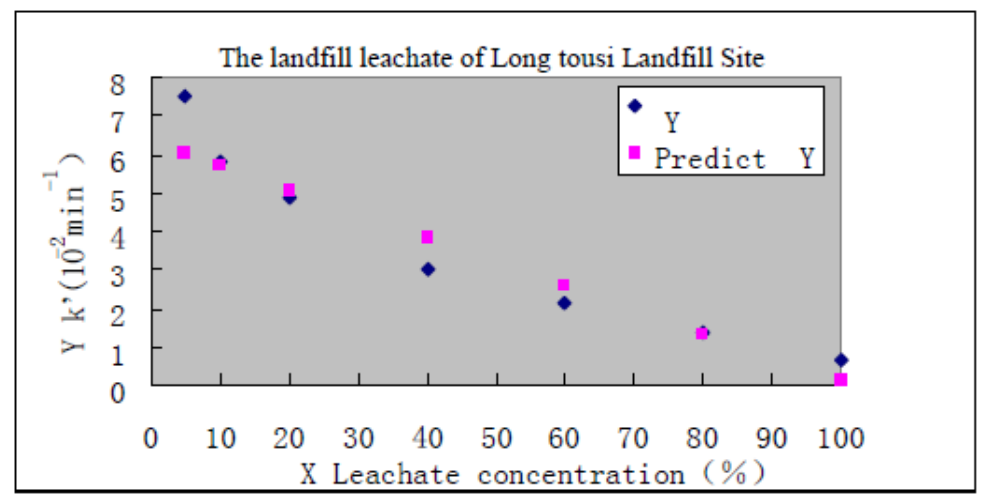

Fig. 2. Linear fitting chart between k' and concentrations of leachate from Long Tousi.

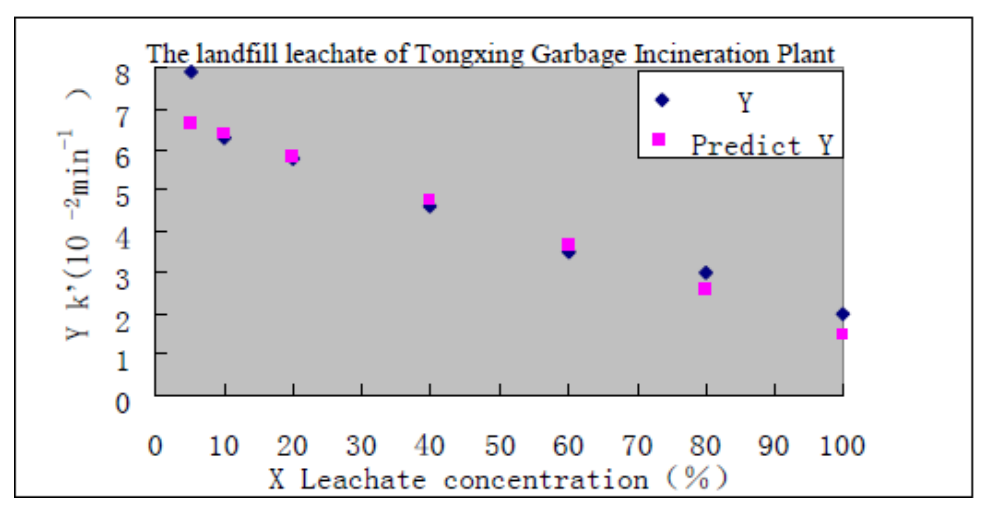

Fig. 3. Linear fitting chart between k' and concentrations of leachate from Tong Xing.

Meanwhile comparing $\mathrm{K}$ 'value at different concentrations of two kinds of the landfill leachate, it is not difficult to find, the landfill leachate of Longtou Temple in the late stage shows stronger biological toxicity than the waste leachate of Tongxing Burning Plant on activated sludge. In addition, between the concentration of $5 \%$ to $10 \% \mathrm{~K}$ 'value shows a big change, the reduction degree of the filtrate of $5 \%$ is not large compared to the initial sludge $\mathrm{K}^{\prime} 8.71$ the extent of the decrease is not large, showing that the effect of the filtrate of $5 \%$ on the sludge is less, while the toxicity of the filtrate of $10 \%$ is greater. The above two points both have a guiding role for the selection of specific processes when biological treating the landfill leachate, and for the determination of the mixed ratio when joining up the sewage plant and combined treating.

\section{Conclusion}

The experimental results show: using the endogenous respiration rate constant $\mathrm{k}$ ' characterizes the biological toxicity that the landfill leachate has on the activated 
sludge has certain scientific reasonability. Moreover, because $\mathrm{K}$ 'directly reflects the biological toxicity effect on the activated sludge, for the selection of specific processes when biological treating the landfill leachate, the determination of the mixed ratio when joining up the sewage plant, and the selection of pretreatment technology of the landfill leachate, it has a certain guiding role.

\section{References}

1. D Alkalay, L Guerrero, J M Lema, et al. Anaerobic treatment of municipal sanitary landfill leachate: the problem of refractory and toxic components. World Journal of Microbiology \& Biotechnology, Vol 14, pp. 309-320, March 1998

2. Shen Yao-liang, Yang Quan-da. Pretreatment of landfill leachate by coagulation-adsorption process. CHINA WATER \& WASTEWATER, Vol 15, pp. 10-14, November 1999 (In Chinese)

3. Shi jia, Xu Yatong, Zhang Shengzhang. Environmental Microbiology Shanghai, East China Normal University, 1993, in press

4. M. Sperandio, Paul Etienne. Estimation of wastewater biodegradable COD fractions by combining respirometric experiments in various $\mathrm{S} 0 / \mathrm{X} 0$ ratios. Water Research, Vol 34, pp. 1 233-1 246, April 2000

5. Li Ping, Wei Weihai, Ren Zaogang, et al. Study of the biodegradability and dynamic simulated experiment on landfill leachate. Environmental Engineering, Vol 21, pp. 7-10, January 2003 (In Chinese) 